\title{
Prolonged Gut Dysbiosis and Fecal Excretion of Hepatitis A Virus in Patients Infected with Human Immunodeficiency Virus
}

\author{
Aya Ishizaka ${ }^{1,2,3}{ }^{(}$, Michiko Koga ${ }^{1}$, Taketoshi Mizutani ${ }^{1,2, *}$, , Lay Ahyoung Lim ${ }^{4}$, Eisuke Adachi ${ }^{4}(\mathbb{D}$, \\ Kazuhiko Ikeuchi $^{4}{ }^{(0)}$, Ryuta Ueda ${ }^{5}$, Haruyo Aoyagi ${ }^{5}$, Satoshi Tanaka ${ }^{6} \mathbb{D}$, Hiroshi Kiyono ${ }^{2,7}$, Tetsuro Matano ${ }^{8,9}{ }^{\circledR}$,

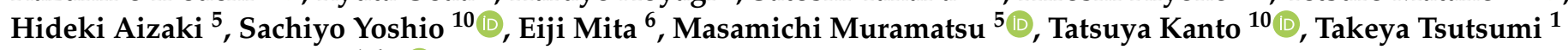 \\ and Hiroshi Yotsuyanagi $1,4, *$ (D)
}

check for updates

Citation: Ishizaka, A.; Koga, M.; Mizutani, T.; Lim, L.A.; Adachi, E.; Ikeuchi, K.; Ueda, R.; Aoyagi, H.; Tanaka, S.; Kiyono, H.; et al. Prolonged Gut Dysbiosis and Fecal Excretion of Hepatitis A Virus in Patients Infected with Human Immunodeficiency Virus. Viruses 2021, 13, 2101. https://doi.org/ $10.3390 / v 13102101$

Academic Editor: Albert Bosch

Received: 17 September 2021

Accepted: 14 October 2021

Published: 18 October 2021

Publisher's Note: MDPI stays neutral with regard to jurisdictional claims in published maps and institutional affiliations.

Copyright: (c) 2021 by the authors. Licensee MDPI, Basel, Switzerland. This article is an open access article distributed under the terms and conditions of the Creative Commons Attribution (CC BY) license (https:// creativecommons.org/licenses/by/ $4.0 /)$.
1 Division of Infectious Diseases, Advanced Clinical Research Center, The Institute of Medical Science, The University of Tokyo, Tokyo 108-8639, Japan; ishizaka@ims.u-tokyo.ac.jp (A.I.); michiko@ims.u-tokyo.ac.jp (M.K.); tsutsumi@ims.u-tokyo.ac.jp (T.T.)

2 International Research and Development Center for Mucosal Vaccines, The Institute of Medical Science, The University of Tokyo, Tokyo 108-8639, Japan; kiyono@ims.u-tokyo.ac.jp

3 Japan Foundation for AIDS Prevention, Tokyo 101-0064, Japan

4 Department of Infectious Diseases and Applied Immunology, IMSUT Hospital of Institute of Medical Science, The University of Tokyo, Tokyo 108-8639, Japan; laylim@insti.kitasato-u.ac.jp (L.A.L.); e-adachi@ims.u-tokyo.ac.jp (E.A.); kikeuchi004@gmail.com (K.I.)

5 Department of Virology II, National Institute of Infectious Diseases, Tokyo 162-8640, Japan; ueda@niid.go.jp (R.U.); aoyagi@nih.go.jp (H.A.); aizaki@nih.go.jp (H.A.); muramatsu@nih.go.jp (M.M.)

6 Department of Gastroenterology and Hepatology, National Hospital Organization Osaka National Hospital, Osaka 540-0006, Japan; tanaka.satoshi.eg@mail.hosp.go.jp (S.T.); mita.eiji.zf@mail.hosp.go.jp (E.M.)

7 CU-UCSD Center for Mucosal Immunology, Allergy and Vaccines (cMAV), Department of Medicine, University of California San Diego, San Diego, CA 92093, USA

8 AIDS Research Center, National Institute of Infectious Diseases, Tokyo 162-8640, Japan; tmatano@nih.go.jp

9 Department of AIDS Vaccine Development, IMSUT Hospital, The Institute of Medical Science, The University of Tokyo, Tokyo 108-8639, Japan

10 The Research Center for Hepatitis and Immunology, National Center for Global Health and Medicine, Chiba 272-8516, Japan; sachiyo@hospk.ncgm.go.jp (S.Y.); kantot@hospk.ncgm.go.jp (T.K.)

* Correspondence: mizutanitaketoshi@g.ecc.u-tokyo.ac.jp (T.M.); yotsudid@ims.u-tokyo.ac.jp (H.Y.)

Abstract: Hepatitis A virus (HAV) causes transient acute infection, and little is known of viral shedding via the duodenum and into the intestinal environment, including the gut microbiome, from the period of infection until after the recovery of symptoms. Therefore, in this study, we aimed to comprehensively observe the amount of virus excreted into the intestinal tract, the changes in the intestinal microbiome, and the level of inflammation during the healing process. We used blood and stool specimens from patients with human immunodeficiency virus who were infected with HAV during the HAV outbreak in Japan in 2018. Moreover, we observed changes in fecal HAV RNA and quantified the plasma cytokine level and gut microbiome by $16 \mathrm{~S}$ rRNA analysis from clinical onset to at least 6 months after healing. HAV was detected from clinical onset up to a period of more than 150 days. Immediately after infection, many pro-inflammatory cytokines were elicited, and some cytokines showed different behaviors. The intestinal microbiome changed significantly after infection (dysbiosis), and the dysbiosis continued for a long time after healing. These observations suggest that the immunocompromised state is associated with prolonged viral shedding into the intestinal tract and delayed recovery of the intestinal environment.

Keywords: HAV; HIV; microbiome; microbiome

\section{Introduction}

Hepatitis A is one of the most common infectious liver diseases worldwide. It is caused by the hepatitis A virus (HAV), a positive-stranded RNA virus belonging to the genus Hepatovirus in the Picornaviridae family [1]. Hepatitis A is generally an acute and 
self-limiting hepatitis disease that rarely causes fulminant hepatitis. The main symptoms of this infection are fever, nausea, and jaundice with acute liver failure. Hepatitis A virus infections are common in developing countries, but sporadic outbreaks have been reported in developed countries [2]. The transmission of HAV mainly occurs via the fecal-oral route through water and food products contaminated with feces. In addition, sexual transmission is a well-recognized mode of HAV transmission, and men who have sex with men (MSM) are known to be at high risk of infection [3,4]. In 2018, an outbreak of hepatitis A was reported in a MSM population in Japan [5,6]. The viral strain in this outbreak was identified as the genotype 1A strain RIVM-HAV16-090, which was involved in a global outbreak in the MSM community in 2016-2017 [5,6].

After ingestion by the fecal-oral route, HAV spreads from the intestine to the liver via portal circulation. Viral particles of HAV that have replicated in the hepatocytes are discharged into the bile and excreted back into the duodenum [7,8]. Previous studies have shown that two different forms of infectious particles are found in HAV-infected individuals. Hepatitis A virus particles in the blood are quasi-enveloped (eHAV), encased in lipid bilayers derived from host cells, and are known to be resistant to neutralizing antibodies and to promote viral replication in liver tissue [9]. On the other hand, virions without envelopes are shed in the feces and remain stable in that environment for a long time, facilitating infection of new hosts $[10,11]$. In early studies, fecal HAV was revealed to be in complex with a specific immunoglobulin A $[12,13]$. There is some evidence that these immunocomplexes are transmitted to the liver via intestinal transcytosis and enhance reinfection of the liver $[14,15]$. However, it is unclear how long the infectivity of a virus that is shed via the intestinal tract actually persists.

Previous reports have shown that HAV RNA can be detected in both blood and feces for a long period of time in immunocompetent patients, even after alanine aminotransferase (ALT) levels have fallen into the normal range [16-18]. Viral shedding in feces occurs from 1 to 2 weeks prior to clinical onset and lasts up to 3 months or longer in immunocompetent patients, while plasma viremia was shown to be detectable for a median period of 42 days [16,17].

In recent years, it has become clear that the gut microbiome plays a role in the progression of liver diseases. Although hundreds of species of commensal bacteria colonize the human gut and have been shown to be deeply involved in liver function, little is known of the profile of the gut microbiome during HAV infection [19]. On the other hand, it has become clear that HIV-positive individuals have an unique gut microbiome profile. In our $16 \mathrm{~S}$ rRNA metagenomic analysis of HIV patients with MSM, we observed that despite long-term viral suppression, the gut microbiome of HIV-infected patients is more aerobic than healthy individuals [20]. The altered gut microbiome in patients with HIV is considered to be influenced by the HIV infection itself, as well as the antiretroviral therapy (ART) regimen [21-23]. Recently, the unique pattern of gut microbiome related to sexual preference has also been well documented [24,25]. Although MSM are considered a high-risk group for HAV and HIV infection, there is limited information on the enterohepatic circulation of HAV when HAV is co-infected in HIV-infected individuals. Furthermore, the correlation between the gut microbiome and the immune dynamics of co-infection such as HAV infection in these patients is not fully understood. In this study, we comprehensively analyzed the correlation between changes in the gut microbiome due to acute HAV infection, and viral shedding and inflammation in the intestinal tract of HIV-infected individuals in a hepatitis A outbreak in the Japanese MSM-community in 2018.

\section{Materials and Methods}

\subsection{Study Subjects and Sample Collection}

A total of 10 patients with chronic HIV infection who were diagnosed with acute hepatitis A, 25 patients with chronic HIV infection who were without acute Hepatitis A, as well as 22 uninfected controls were enrolled in this study. Among the HIV positive pa- 
tients, all of the patients were MSM and had been treated with antiretroviral therapy (ART) for more than 22 months. None of the patients with HAV took proton pump inhibitors. For clinical sample collection, among the 10 patients with HAV infection, 7 patients provided stool samples continuously for 68 to 225 days. Blood samples were obtained from 7 patients, including 3 patients who provided consent for cytokine measurement. None of the participants took antibiotics within the previous 2 weeks from stool collection.

\subsection{Measuring HAV RNA Load in Fecal Samples}

Patient feces/PBS (-) suspension (10\%) was prepared, vigorously agitated, and centrifuged at 12,000 rpm for $20 \mathrm{~min}$. The centrifuged supernatant was used for RNA purification, and RNA was purified according to the protocol of QIAamp Viral RNA Mini kit (Qiagen, Valencia, CA, USA), followed by DNase treatment using DNase I (Takara Bio), and extracted RNA was used as a template for RT-PCR. The cDNA was synthesized by SuperScript II RNase H- Reverse Transcriptase (Invitrogen, Carlsbad, CA, USA) according to the protocol, and then quantized using TaqMan Universal PCR Master mix with ABI PRISM 7700 system (Applied Biosystems, Foster City, CA, USA). The PCR condition was as follows: $50^{\circ} \mathrm{C}$ for $2 \mathrm{~min}, 95^{\circ} \mathrm{C}$ for $10 \mathrm{~min}$ once, then $95^{\circ} \mathrm{C}$ for $15 \mathrm{~s}, 56^{\circ} \mathrm{C}$ for $1 \mathrm{~min} 45$ times. Forward primer: 5'-AGG GTA ACA GCG GCG GAT AT-3' (nt 449 to 468); reverse primer: 5'-ACA GCC CTG ACA RTC AAT YCA CT-3' (nt 557 to 535); and TaqMan Probe: 5'-FAMAGA CAA AAA CCA TTC AAC RCC GRA GGA C-TAMRA-3' (nt 482 to 509). The primer location was based on the HAV strain, AH1/Japan (GenBank accession no. AB020564).

\subsection{DNA Extraction}

Stool samples were washed three times in a SM-plus buffer $(100 \mathrm{mM} \mathrm{NaCl}, 50 \mathrm{mM}$ Tris- $\mathrm{HCl}$ [pH 7.4], $8 \mathrm{mM} \mathrm{MgSO} 4,5 \mathrm{mM} \mathrm{CaCl}_{2}$, and $0.01 \%$ gelatin) and centrifuged to remove the supernatant. The pellet was resuspended in a SM-plus buffer and large debris were removed by filtering the stool suspension through a $100 \mu \mathrm{m}$ cell strainer. The resulting suspension was incubated with $20 \mathrm{mM}$ ethylenediaminetetraacetic acid (EDTA), $500 \mathrm{U} / \mathrm{mL}$ achromopeptidase (Sigma-Aldrich, St. Louis, MO, USA), and $0.1 \mathrm{mg} / \mathrm{mL}$ human lysozyme (Sigma-Aldrich) at $37^{\circ} \mathrm{C}$ for $1 \mathrm{~h}$, followed by overnight incubation with $50 \mu \mathrm{g} / \mathrm{mL}$ protease $\mathrm{K}$ (Nacalai Tesque, Kyoto, Japan) and $0.05 \%$ sodium dodecyl sulfate at $37^{\circ} \mathrm{C}$. Bacterial DNA was extracted using the phenol-chloroform method and purified with a QIAquick PCR Purification Kit (Qiagen).

\subsection{Construction of DNA Library and Sequencing}

The 16S V3 and V4 regions were amplified using the KAPA SYBR Fast qPCR Kit (Kapa Biosystems, Wilmington, MA, USA). The primary PCR protocol comprised an initialization step at $94^{\circ} \mathrm{C}$ for $2 \mathrm{~min}$ and 20 cycles at $98^{\circ} \mathrm{C}$ for $10 \mathrm{~s}$ and $68^{\circ} \mathrm{C}$ for $15 \mathrm{~s}$ using the following primer pair: Forward primer, $5^{\prime}$-ACA CGA CGC TCT TCC GAT CTC CTA CGG GNG GCW GCA G-3' and reverse primer, 5'-GAC GTG TGC TCT TCC GAT CTG ACT ACH VGG GTA TCT AAT CC-3'. The PCR amplicon was purified with Agencourt AMPure XP magnetic beads (Beckman Coulter) per the manufacturer's instructions. The secondary PCR protocol consisted of an initialization step at $94{ }^{\circ} \mathrm{C}$ for $45 \mathrm{~s}$, and 8 cycles at $98{ }^{\circ} \mathrm{C}$ for $15 \mathrm{~s}, 50^{\circ} \mathrm{C}$ for $30 \mathrm{~s}$, and $72{ }^{\circ} \mathrm{C}$ for $30 \mathrm{~s}$ using NEB Next Multiplex Oligos for Illumina (Dual Index Primers Set 1; New England Biolabs [NEB], Ipswich, MA, USA). The final PCR amplicon was purified with Agencourt AMPure XP magnetic beads and verified using agarose gel electrophoresis. The samples were normalized and pooled, followed by sequencing on the MiSeq platform using the MiSeq Reagent Kit V3 (Illumina, San Diego, CA, USA).

\subsection{Sequence Data Analyses}

The $16 \mathrm{~S}$ rRNA reads were analyzed using the Quantitative Insights Into Microbial Ecology version 2 (QIIME2) pipeline version 2020.6 [26]. Paired-end reads were merged and denoised using DADA2 [27]. Sequences were clustered into operational taxonomic 
units (OTUs) at a threshold of $97 \%$ sequence identity against the Silva reference database version 138 [28].

\subsection{Measurement of the Cytokine Profile}

Blood samples were obtained from patients with HAV infection. Plasma cytokine levels were quantified using a Bio-Plex System (Bio-Rad Laboratories, Hercules, CA, USA). The measurement was performed using multiplex assay kits, Bio-Plex Pro Human Chemokine Panel, 40-Plex \#171AK99MR2, and Bio-Plex Pro Human Inflammation Panel 1, 37-Plex \#171AL001M in accordance with the manufacturer's specifications.

\subsection{RNA Purification and $q R T-P C R$ Analysis}

Short Intracellular HIV RNA was measured by a method previously described [21]. For the analysis of the RNA, a portion of small RNA $(<200 \mathrm{nt})$ from patient blood-derived PBMC was purified using Isogen II (Nippon Gene, Toyama, Japan). The cDNA was synthesized using a $5 \times$ miScript HiFlex Buffer (Qiagen, Valencia, CA) supplied with the miScript II RT kit. Amplification reactions were performed on a CFX96 real-time PCR detection system (Bio-Rad Laboratories) using Premix Ex Taq [Probe qPCR] (TaKaRa Bio). The amount of RNA copies was calculated per $10^{6}$ peripheral blood mononuclear cells (PBMCs).

\section{Results}

\subsection{General Characteristics of Participants}

During the period from June 2018 to March 2020, a total of 10 patients with chronic HIV infection were diagnosed as having acute HAV infection. All of the patients were male and MSM. The median (interquartile range) age was 46 (36.8-52.3) years for the patients with HIV and acute HAV infection, 47 (42-50.5) years for the $25 \mathrm{HIV}$ patients in the comparison group, and 45 (34-50.3) years for the 22 healthy controls. All of the patients were on $\mathrm{ART}$, the $\mathrm{CD} 4$ count according to the most recent test before HAV infection was 579 (483-707.5) cells $/ \mu \mathrm{L}$, and the HIV viral load was under the detection limit (Table 1). Detailed clinical information for 10 patients is given in Tables 2 and 3. Five of these patients had underlying diseases: Insomnia, atopy, hypertension, and dyslipidemia (Table 2). In Table 3, the values of liver markers (AST, ALT, and T-Bil) and antibody levels (HA-IgM) during HAV infection were shown.

Table 1. Comparison of the characteristics among HIV patients with or without hepatitis A and healthy controls.

\begin{tabular}{cccc}
\hline & HIV and Acute HAV & HIV Alone & Healthy Controls \\
\hline Total patients (No.) & 10 & 25 & 22 \\
Males (No.) & $10(100 \%)$ & $25(100 \%)$ & $22(100 \%)$ \\
MSM (No.) & $10(100 \%)$ & $24(96 \%)$ & - \\
Age in years & $46(36.8-52.3)$ & $47(42-50.5)$ & $45(34-50.3)$ \\
BMI & $23.6(20.8-25.2)$ & $23.6(20.8-26.1)$ & - \\
HIV Viral load < 20 copies/mL (No.) & $10(100 \%)^{1}$ & $25(100 \%)$ & - \\
CD4 count (cells/ul) & $579(483-707.5)^{1}$ & $613(517-731.5)$ & - \\
Duration of ART (years) & $8(3.5-14)$ & $8(6.5-13)$ & - \\
Peak serum ALT (IU/L) & $3540(581.3-4001.3)$ & - & - \\
Peak serum AST (IU/L) & $1958(1288-3673.8)$ & - & - \\
Peak serum T-Bil (mg/dL) & $6.4(3.0-11.8)$ & & \\
\hline
\end{tabular}

Data are shown as the median and interquartile range unless otherwise described. ${ }^{1}$ Prior to HAV infection. BMI: Body mass index; AST: Aspartate aminotransferase; -: not applicable. 
Table 2. Basic characteristics of HIV patients with hepatitis A.

\begin{tabular}{|c|c|c|c|c|c|c|c|c|c|}
\hline $\begin{array}{c}\text { Patient } \\
\text { No. }\end{array}$ & Age & BMI & $\begin{array}{c}\text { Years after } \\
\text { HIV } \\
\text { Diagnosis }\end{array}$ & $\begin{array}{l}\text { CD4 } \\
\text { Counts } \\
(/ \mu L)^{1}\end{array}$ & $\begin{array}{c}\text { CD8 } \\
\text { Counts } \\
(/ \mu L)^{1}\end{array}$ & $\begin{array}{c}\text { CD4/CD8 } \\
\text { Ratio }^{1}\end{array}$ & $\begin{array}{c}\text { HIV-RNA } \\
\text { Load } \\
{\text { (Copies } / \mathrm{mL})^{1}}^{1}\end{array}$ & ART Regimen & $\begin{array}{l}\text { Underlying } \\
\text { Health } \\
\text { Conditions }\end{array}$ \\
\hline 20 & 40 & 24.2 & 9 & 508 & 656 & 0.8 & $<20$ & TAF/FTC RPV & Dyslipidemia \\
\hline 213 & 56 & 24.8 & 24 & 538 & 1035 & 0.5 & $<20$ & TDF/FTC DTG & Insomnia \\
\hline 463 & 49 & 27.7 & 20 & 955 & 1124 & 0.8 & $<20$ & $\mathrm{ABC} / 3 \mathrm{TC} / \mathrm{DTG}$ & $\begin{array}{l}\text { Hypertension, } \\
\text { dyslipidemia }\end{array}$ \\
\hline 708 & 44 & 23.1 & 12 & 490 & 378 & 1.3 & $<20$ & $\mathrm{ABC} / 3 \mathrm{TC} \mathrm{DRV} / \mathrm{c}$ & - \\
\hline 832 & 53 & 24.2 & 7 & 817 & 839 & 1 & $<20$ & TAF/FTC DTG & - \\
\hline 989 & 36 & 21.3 & 10 & 620 & 589 & 1.1 & $<20$ & TAF/FTC/RPV & Dyslipidemia \\
\hline 1141 & 48 & 26.4 & 6 & 671 & 447 & 1.5 & $<20$ & ABC/3TC RAL & - \\
\hline 1292 & 52 & 19.2 & 4 & 293 & 605 & 0.5 & $<20$ & TAF/FTC DTG & - \\
\hline 1334 & 27 & 17.7 & 2 & 656 & 525 & 1.2 & $<20$ & TAF/FTC DTG & - \\
\hline 1349 & 37 & 22.0 & 1 & 462 & 539 & 0.9 & $<20$ & $\mathrm{ABC} / 3 \mathrm{TC} / \mathrm{DTG}$ & Atopic dermatitis \\
\hline
\end{tabular}

${ }^{1}$ Prior to HAV infection. TAF: Tenofovir alafenamide fumarate; FTC: Emtricitabine; RPV: Rilpivirine; TDF: Tenofovir disoproxil fumarate; DTG: Dolutegravir; ABC: Abacavir; 3TC: Lamivudine; DRV/c: Darunavir/cobicistat; RAL: Raltegravir; -: no underlying health conditions.

Table 3. Laboratory data associated with hepatitis A.

\begin{tabular}{cccccc}
\hline \multirow{2}{*}{ Patient No. } & $\begin{array}{c}\text { Initial HA-IgM } \\
\text { (s/co) }\end{array}$ & \multicolumn{2}{c}{ ALT (IU/L) } & \multirow{2}{*}{$\begin{array}{c}\text { Max AST } \\
\text { (IU/L) }\end{array}$} & $\begin{array}{c}\text { Max T-Bil } \\
\text { (mg/dL) }\end{array}$ \\
\cline { 3 - 4 } & 5.7 & Before & Max & & \\
20 & 0.58 & 34 & 8877 & 6996 & 7.8 \\
213 & 1.09 & 114 & 3515 & 3530 & 6.6 \\
463 & 3.25 & 16 & 2589 & 1722 & 3.1 \\
708 & 3.24 & 21 & 3985 & 2194 & 15.2 \\
832 & 11.2 & 11 & 677 & 4105 & 6.2 \\
989 & 11.7 & 26 & 294 & 1400 & 22.8 \\
1141 & 2.04 & 10 & 174 & 952 & 2.5 \\
1292 & 10.1 & 8 & 4050 & 2860 & 2.2 \\
1334 & 11.6 & 22 & 3565 & 1663 & 10.6 \\
1349 & & & & & 4.5 \\
\hline
\end{tabular}

3.2. Time Course of Viral Shedding and Clinical Markers during HAV Co-Infection among Patients with Chronic HIV Infection

During the course of HAV infection, the CD4 count and HIV viral load were not affected by the acute HAV infection (Figure 1a, and data not shown). Intracellular short HIV RNA, which reflects persistent transactivation of the HIV promoter and well-correlates with the levels of $\mathrm{CD} 8^{+}$T-cell activation in aviremic patients with long-term successful ART [29], was not detected as well (Figure 1b). Levels of liver function marker, such as the levels of ALT and total bilirubin (T-Bil) were shown in Figure 1c,d. The ALT levels were observed to be the highest at clinical onset of HAV infection, while the levels of T-Bil peak at several days after onset. The values of those markers rapidly decreased over time, reaching normal levels around 30 days after onset in all of the patients, except for patient no. 989, whose ALT and T-Bil levels were observed to rebound (Figure 1c,d). The HAV viral load was at the highest titer level in the first point sample of each patient and gradually decreased over time (Figure 1e). Among these patients, three patients (no. 20, 1141, and 1334) and one patient (no. 213) were positive for HAV RNA for over 100 days and 50 days after clinical onset, respectively. As for fecal excretion of HAV RNA, all of the patients whose feces were continuously collected were positive for HAV RNA for 100 days after clinical onset (Figure 1f). Among these, patient no. 1349 was positive for HAV RNA in his feces at day 168 . 
a

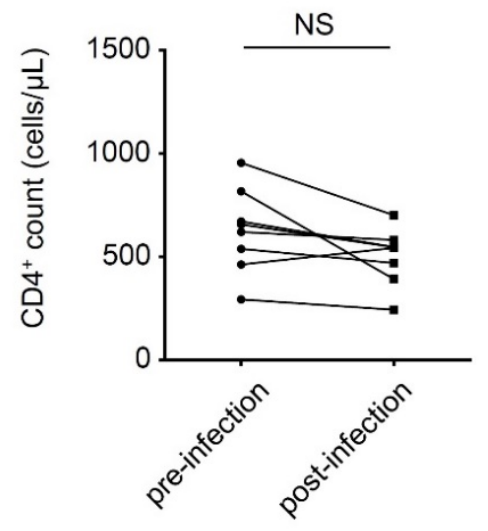

C

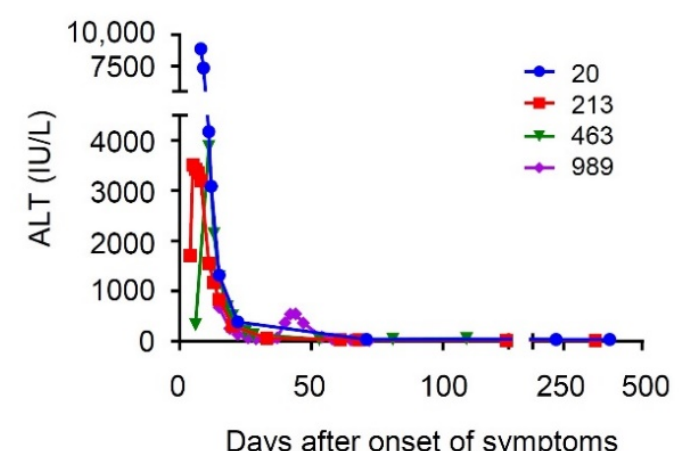

e

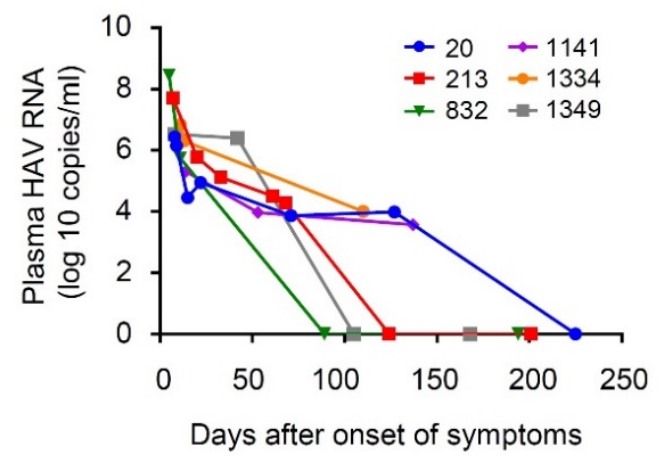

b

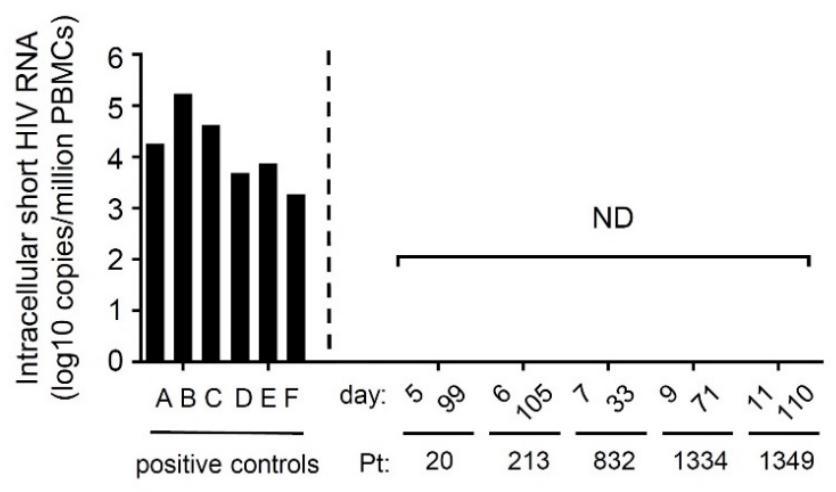

d

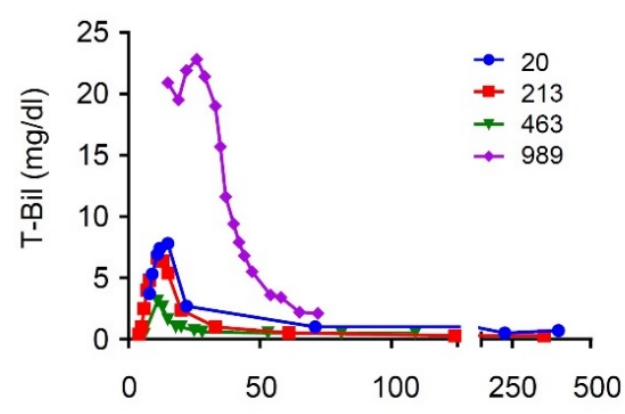

Days after onset of symptoms

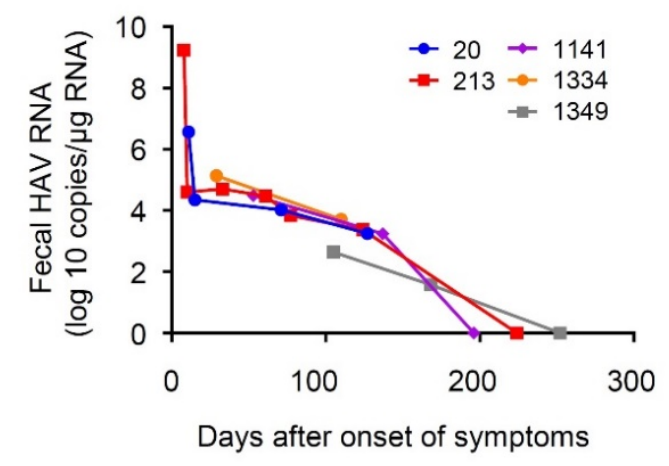

Figure 1. Changes in the levels of human immunodeficiency virus (HIV) in the blood and hepatitis A virus (HAV) excretion in the stool during the period from immediately after acute HAV infection to after healing. The day of clinical onset was set to day 1 on the horizontal axis; (a) CD4 count (cells/mL) of patients with HIV after HAV infection; (b) intracellular short HIV transcripts in peripheral blood mononuclear cells (PBMCs) (copies/million PBMCs). Patients A-F shown on the left were positive controls for the transcripts; (c) the levels of alanine aminotransferase (ALT) in plasma fractions of patients $(\mathrm{U} / \mathrm{mL}) ;(\mathbf{d})$ the levels of total bilirubin (T-Bil) in plasma fraction of patients $(\mathrm{mg} / \mathrm{dL}) ;(\mathbf{e}, \mathbf{f})$ the levels of HAV-RNA

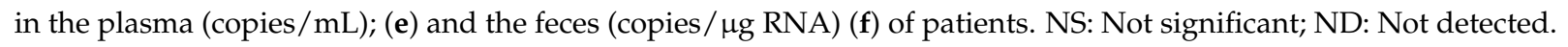

\subsection{Time Course of Chemokine Expression during Acute HAV Infection}

Several chemokines, such as CXCL9, CXCL10, CXCL11, and CXCL12 were previously described as being involved in liver diseases [30-33]. These chemokines were observed to be present in high levels at clinical onset and gradually decreased over a number of days in two of the patients, although this could not be fully determined in Patient no. 463 
(Figure 2a). Among these chemokines, CXCL9, CXCL10, and CXCL11 are known as interferon gamma (IFN- $\gamma$ )-induced chemokines and are involved in Th1 immune response [34]. Similar secretion kinetics were observed for IFN- $\gamma$ itself and for CXCL16 (Figure 2b), which has been known to induce migration of natural killer T (NKT) cells, one of the most efficient producers of IFN- $\gamma$ [35]. In addition, a similar pattern of change was observed in several pro-inflammatory cytokines, such as tumor necrosis factor (TNF)- $\alpha$, interleukin (IL)-1 $\beta$, and IL-6 (Figure 2c), as well as chemokines that induce migration of monocytes and macrophages, such as CCL1, CCL2, and CCL25 (Figure 2d). The decrease in the level of these chemokines was similar to ALT, as shown in Figure 1d. On the other hand, some chemokines did not decrease, such as CXCL1, CXCL2, and CXCL6, which are reported to bind to CXCR2 receptors and mediate neutrophil trafficking [36], showing sustained or elevated secretion kinetics (Figure 2e).

a
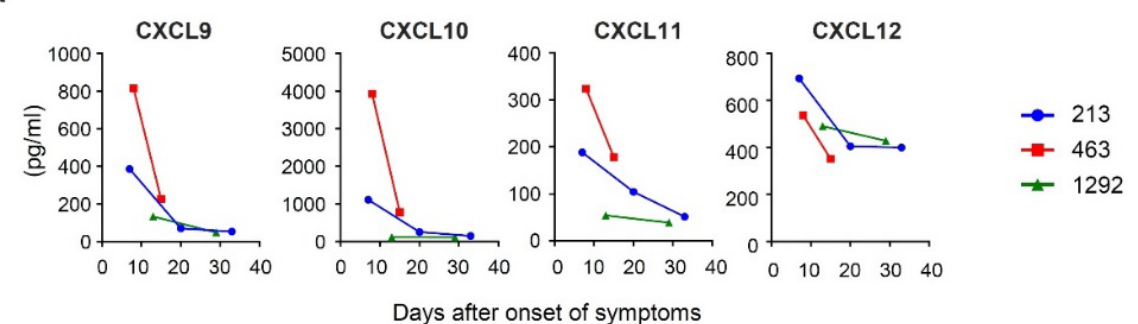

b

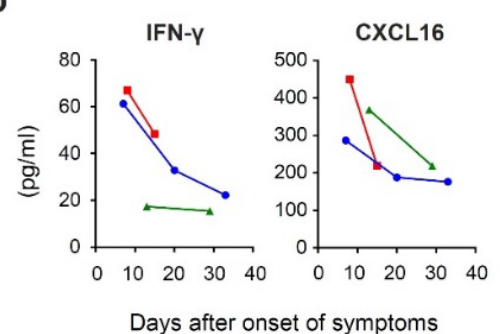

C
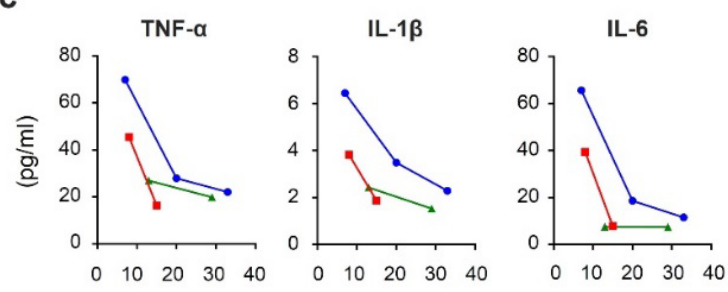

d

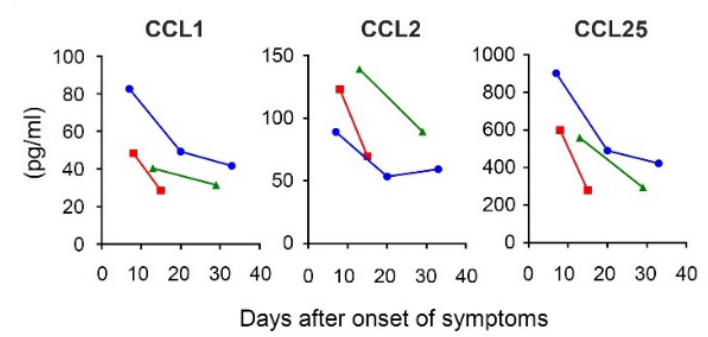

e

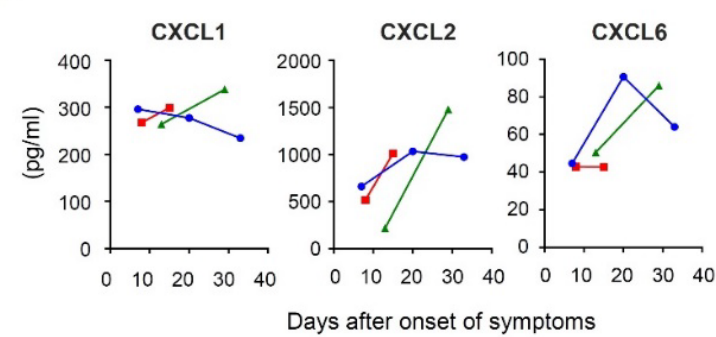

Figure 2. Changes of cytokine profile after clinical onset of HAV infection. Measurements of (a) CXCL9, CXCL10, CXCL11, and CXCL12; (b) IFN- $\gamma$ and CXCL16; (c) tumor necrosis factor (TNF)- $\alpha$, interleukin (IL)-1 $\beta$, and IL-6; (d) CCL1, CCl2, and CCL25; and (e) CXCL1, CXCL2, and CXCL6 in serum of patients. The clinical onset was set to day 1.

\subsection{Prolonged Fecal Dysbiosis after HAV Infection}

To monitor the impact of HAV infection on the gut microbiome, we performed $16 \mathrm{~S}$ ribosomal RNA sequencing and investigated the microbial distributions at the phylum level. The dominant phyla in the gut microbe were Firmicutes, Proteobacteria, Bacteroidetes, and Actinobacteria in both patients with chronic HIV infection and healthy controls (Figure 3a). We monitored the sequential changes in the gut microbiome during acute HAV infection and after recovery from infection. We observed the temporary enrichment of low abundance phyla at clinical onset, such as the phyla Fusobacteria and Desulfobacterota (Figure $3 b, c$ ). This result was consistent with the observation of a transient increase and subsequent decrease in the alpha-diversity of these patients. Alpha diversity determined by the observed OTUs and Shannon index values were higher in patients with HAV after 
clinical onset compared to those of patients without HAV (Figure 3d,e). Both observed OTUs and Shannon index values were gradually decreased over a duration of 100 days to a degree similar to those of patients without HAV. In addition, among three out of the five patients we analyzed, we observed enrichment in Actinobacteria and lower abundance of Proteobacteria compared to patients without HAV (Figure 3b). In the other two patients, we observed enrichment of Bacteroidota and lower abundance of Proteobacteria (Figure 3c). The composition of microbiome at the phylum level became similar to patients without HAV over a duration of about 100 days (Figure $3 b, c)$. Within the phyla Actinobacteria and Bacteroidota, the genera Bifidobacterium and Bacteroides, respectively were the taxa majorly responsible for enrichment of these phyla, respectively (Figure 3f,g). Together, the impact of HAV infection on the gut microbiome continued not only during acute HAV infection, but also for a long time after recovery of clinical symptoms.

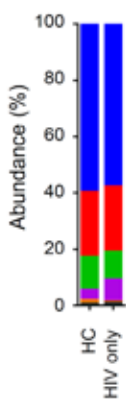

d

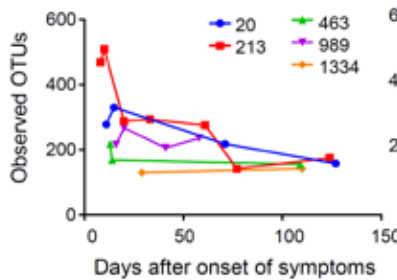

f

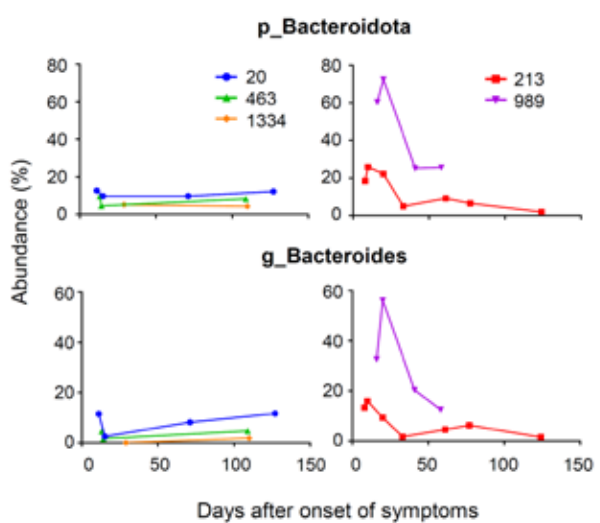

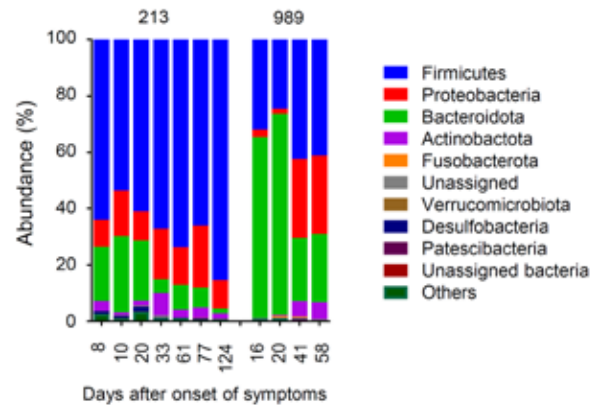

e

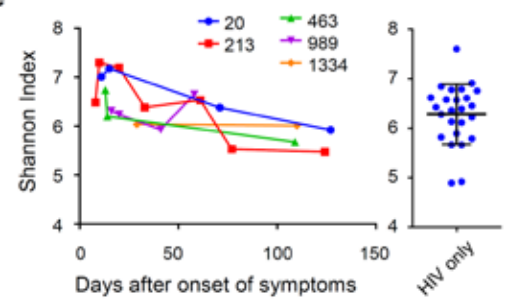

g

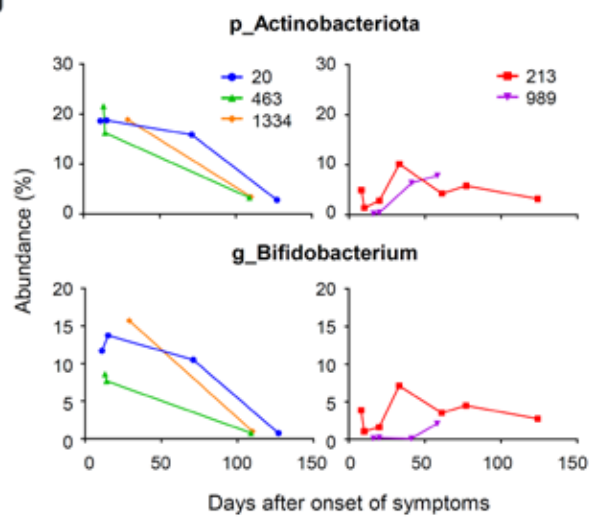

Figure 3. 16S rRNA analysis of changes in the intestinal microbiome of patients after hepatitis A virus (HAV) infection. (a-e) Bacterial taxa profile (Phyla) in the gut microbiome of each patient: (a) Average of bacterial taxa profile (Phyla) of healthy cohorts (HC), patients with HIV (not with $\mathrm{HAV}) ;(\mathbf{b}, \mathbf{c})$ the taxa profile (Phyla); (d) observed operational taxonomic units (OTUs); (e) Shannon index of the gut microbiome of individual patients; and $(\mathbf{f}, \mathbf{g})$ bacterial taxa profile (Phyla and genus) in the gut microbiome of each patient. The clinical onset was set to day 1 . Due to the small number of analyses, statistically significant differences in changes in the gut microbiota could not be confirmed. 


\section{Discussion}

Prior to the current study, only two published studies had followed the duration of viremia and fecal excretion of HAV RNA after HAV infection in HIV patients. One analysis compared 15 HIV-1-infected MSM with an equal number of age-matched non-HIV-infected patients and reported that the HAV load was higher in HIV-1-infected patients than in non-infected patients. In addition, the duration of viremia in HIV-1-infected patients (median 53 days) was significantly longer than in non-infected patients (median 22 days), suggesting that HIV-1 infection is associated with prolonged HAV viremia [37]. The other study, albeit a small analysis of only one patient, reported that a patient with HIV who was ART-naïve and suffering from acute HAV infection exhibited prolonged plasma viremia for up to 256 days and Hepatitis A virus RNA was detected from feces at day 106 after the onset of symptoms [18]. In the current study, we observed that HAV viremia lasted for over 100 days after the onset of symptoms in three out of six patients with HIV. In addition, fecal shedding of HAV RNA in these patients lasted for more than 100 days. Although all the patients were on ART and achieved virologic suppression, this was clearly longer than the immunocompetent patients, which was previously reported as a median period of 42 days for $\mathrm{HAV}$ viremia and 81 days for fecal excretion [14]. In consideration of previous studies showing that $\mathrm{CD} 4^{+} \mathrm{T}$ cells play an important role in terminating HAV infection in a chimpanzee model [38], our observations on HAV viremia fecal shedding of HAV RNA suggest that HIV-infected patients need a longer period of time to eliminate HAV from their bodies. This may be due to the chronic immune exhaustion that has been reported in HIV patients [39].

We observed that proinflammatory cytokines, as well as chemokines involved in the cellular immune response were of high levels at clinical onset and decreased over time. Reduction of these cytokines and chemokines occurred at the same timing as the decrease in markers of liver damage. This is in line with earlier studies, showing that the host immune response, such as IFN- $\gamma$-producing cytotoxic $\mathrm{CD}^{+} \mathrm{T}$ cells, contributes to liver damage during acute HAV infection [40,41]. In addition, we observed no effect of acute HAV infection on CD4 counts, plasma HIV viral load, as well as cellular HIV RNA, which was consistent with the study on the ART-naïve patient with HAV infection [18]. This may be due to the fact that the acute HAV infection induces only a limited type of I IFN response [42]. It is known that HAV blocks the innate immune signaling pathway via digesting key proteins of the signaling pathway that induce the type I INF synthesis, such as TIR-domain-containing adapter-inducing interferon- $\beta$ (TRIF) [43], mitochondrial antiviral signaling (MAVS) protein [44], and NF-kappa-B essential modulator (NEMO) [45]. In chimpanzee models, type I IFN is induced in a very early stage of HAV infection, but it is rapidly downregulated when the level of HAV RNA increases in the liver [46]. The attenuation of IFN induction in the early stages of infection may result in the limited activation of $\mathrm{CD}^{+} \mathrm{T}$ cells that harbor HIV proviruses, and is thus less likely to lead to the transactivation of HIV promoter. On the other hand, the secretion levels of chemokines CXCL1, CXCL2, and CXCL6 did not decrease even after ALT reached normal levels. This may be due to HAV shedding and gut dysbiosis that continues even after the ALT level has decreased to the normal range. Previous reports have shown that CXCL1, 2, and 6 have a function in the chemotaxis of neutrophils to sites of inflammation [36]. This observation suggests that the immune response continues consistently even after the acute infection has subsided. The effect of HIV infection on the clinical course of hepatitis A needs to be further evaluated by comparing these patients with patients infected with HAV without HIV infection.

Earlier studies have revealed the association between the gut dysbiosis and different chronic liver diseases, such as chronic infection with hepatitis B virus (HBV) or hepatitis $\mathrm{C}$ virus (HCV), as well as nonalcoholic fatty liver disease. However, to the best of our knowledge, there have been no reports of gut microbiome analysis in patients with acute HAV. This may due to the fact that hepatitis A is an acute, self-limiting infection, and there is difficulty in collecting clinical samples serially for an extended period, including the 
period of post-recovery of symptoms. However, given that the gut microbiome is closely related with bile acid metabolism and circulation, it is important to clarify the gut dysbiosis in acute hepatitis to better understand the pathogenesis of the disease. In chronic liver diseases, the relative composition of gut microbiome is reported to be changed by the increasing proportion of facultative anaerobic bacteria, as well as the decreasing proportion of strictly anaerobic bacteria. For example, depletion of Bifidobacterium and Bacteroides, as well as enrichment of Proteobacteria were reported in patients with chronic HBV infection and those with cirrhosis [47-49]. In chronic HCV infection, an increasing abundance of Prevotella, Faecalibacterium, Acinetobacter, Veillonella, as well as Phascolarctobacterium was reported, and gut dysbiosis was linked to the progression of the disease [50]. However, the gut dysbiosis we found in patients with acute hepatitis A was different from that found in patients with chronic liver disease. The difference in dysbiosis may be due to the different effects of chronic inflammation associated with chronic liver disease and acute liver injury. One explanation for this is the fact that we have observed a transient increase in OTU immediately after the infection (Figure 3d). The cause may be due to direct effects, such as physical contact between the virus and intestinal bacteria, in addition to the effects of inflammation during acute infection when a large amount of virus is discharged into the intestinal tract. Given that bile has a function of neutralizing stomach acid, the rapidly decreased liver function due to the HAV infection can result in lower $\mathrm{pH}$ in the gut. The intestinal $\mathrm{pH}$ can greatly influence the microbial composition in the gut [51]. A previous study on the impact of mildly acidic $\mathrm{pH}$ on the growth of different species of fecal bacteria showed that the species within Bifidobacterium grew well, but Proteobacteria grew poorly at $\mathrm{pH} 5.5$ than at $\mathrm{pH} 6.7$ [52]. We observed a temporary reduction of the phylum Proteobacteria, as well as an increase of the genera Bifidobacterium in three out of five patients with HIV and acute HAV infection. The peak of gut dysbiosis that we observed was about 2 to 4 weeks after clinical onset, which succeeds the peak of ALT and T-Bil. Therefore, this gut dysbiosis may reflect a decrease in the $\mathrm{pH}$ of the intestines. In addition, previous reports revealed that specific bacteria are involved in the metabolism of specific types of bile acids [53,54]. Taken together, the interaction between the abnormal bile secretion and alteration of gut microbiome may be one of the reasons why gut dysbiosis continues in patients with acute HAV infection, even after recovery from the clinical symptoms.

One of the limitations of this study was the evaluation of limited samples, which may introduce bias owing to individual differences and the impact of the ART regimen. To date, individual and combinations of antiretroviral drugs have been reported to affect the gut microbiome [23]. For example, a protease inhibitor-based regimen was reported to be associated more with microbial translocation and gut endothelial damage as compared with a non-nucleoside reverse transcriptase inhibitors-based regimen [55]. To date, there are few studies on ARVs and the gut microbiome, and little is known on this issue. However, the results of this study, together with previous reports, suggest that HIV-infected individuals shed HAV virus in their feces for a long period of time. Furthermore, this study shows that the intestinal microbiome of HIV-infected individuals changes significantly during the acute phase of HAV infection, and that recovery takes time even after the symptoms have subsided. For a more detailed understanding, it would be important to make a direct comparison between the HAV patients with and without HIV in HAV viral load in blood and feces, as well as the HAV-related changes in the gut microbiota. The role of enteric bacteria in the enterohepatic circulation of HAV is currently unknown, but it may lead to important insights into understanding the life cycle of HAV. In the future, it is expected that the improved understanding of the intestinal environment, including the gut microbiome, will lead to a better understanding of the pathogenesis of hepatitis $\mathrm{A}$ and the interaction between the host and the pathogen. 
Author Contributions: Conceptualization, A.I., M.K., T.M. (Taketoshi Mizutani), M.M., T.T. and H.Y.; methodology, A.I., M.K., T.M. (Taketoshi Mizutani) and T.T.; formal analysis, A.I. and T.M.; investigation, A.I., T.M. (Taketoshi Mizutani), R.U., H.A. (Haruyo Aoyagi) and S.Y.; resources, M.K., L.A.L., E.A., K.I., S.T., E.M., T.T. and H.Y.; data curation, M.K., L.A.L., E.A., K.I. and T.T.; writingoriginal draft preparation, A.I. and T.M. (Taketoshi Mizutani); writing-review and editing, M.K., T.T. and H.Y.; visualization, A.I. and T.M. (Taketoshi Mizutani); supervision, H.Ai., S.Y., T.K. and H.Y.; funding acquisition, H.K., T.M. (Tetsuro Matano), H.A. (Hideki Aizaki), S.Y. and H.Y. All authors have read and agreed to the published version of the manuscript.

Funding: This research was funded by the Japan Agency for Medical Research and Development (AMED) (18kk0205011, 20jk0210022, 20fk0108122), AMED-JICA (the Science and Technology Research Partnership for Sustainable Development: SATREPS) (20jm0110012h0006), Ministry of Health, Labour, and Welfare of Japan (19HC1001, 21HC2001 and 21HB2005), and Japan Society for the Promotion of Science (JSPS) KAKENHI (JP18H05280).

Institutional Review Board Statement: The study was conducted according to the guidelines of the Declaration of Helsinki, and approved by the Institutional Review Board of the Institute of Medical Science, the University of Tokyo (28-55-0330, 30-35-A0803, and 30-49-B0920).

Informed Consent Statement: Informed consent was obtained from all of the subjects involved in the study. Written informed consent has been obtained from the patients to publish this paper. This research is not a case study.

Data Availability Statement: The data presented in this study are available on request from the corresponding authors.

Acknowledgments: We thank all of the patients and healthy volunteers who participated in this study. Naoko Nishiyama for technical assistance with the experiments; Tomoe Senkoji and Megumi Kubota for assistance in clinical data management and Masako Ozawa, Akari Fukuda, Miyuki Shirai, and Etsuko Nagai for assistance in clinical sample collection.

Conflicts of Interest: The authors declare no conflict of interest.

\section{References}

1. Lemon, S.M.; Ott, J.J.; Van Damme, P.; Shouval, D. Type A viral hepatitis: A summary and update on the molecular virology, epidemiology, pathogenesis and prevention. J. Hepatol. 2018, 68, 167-184. [CrossRef] [PubMed]

2. Franco, E.; Meleleo, C.; Serino, L.; Sorbara, D.; Zaratti, L. Hepatitis A: Epidemiology and prevention in developing countries. World J. Hepatol. 2012, 4, 68-73. [CrossRef] [PubMed]

3. Villano, S.A.; Nelson, K.E.; Vlahov, D.; Purcell, R.H.; Saah, A.J.; Thomas, D.L. Hepatitis A among homosexual men and injection drug users: More evidence for vaccination. Clin. Infect. Dis. 1997, 25, 726-728. [CrossRef] [PubMed]

4. Mitchell, H.; Hughes, G. Recent epidemiology of sexually transmissible enteric infections in men who have sex with men. Curr. Opin. Infect. Dis. 2018, 31, 50-56. [CrossRef]

5. Tanaka, S.; Kishi, T.; Ishihara, A.; Watanabe, D.; Uehira, T.; Ishida, H.; Shirasaka, T.; Mita, E. Outbreak of hepatitis A linked to European outbreaks among men who have sex with men in Osaka, Japan, from March to July 2018. Hepatol. Res. 2019, 49, 705-710. [CrossRef] [PubMed]

6. Koga, M.; Lim, L.A.; Ogishi, M.; Satoh, H.; Kikuchi, T.; Adachi, E.; Sugiyama, R.; Kiyohara, T.; Suzuki, R.; Muramatsu, M.; et al. Comparison of the Clinical Features of Hepatitis A in People Living with HIV between Pandemics in 1999-2000 and 2017-2018 in the Metropolitan Area of Japan. Jpn. J. Infect. Dis. 2020, 73, 89-95. [CrossRef]

7. Castaneda, D.; Gonzalez, A.J.; Alomari, M.; Tandon, K.; Zervos, X.B. From hepatitis A to E: A critical review of viral hepatitis. World J. Gastroenterol. 2021, 27, 1691-1715. [CrossRef]

8. Counihan, N.A.; Anderson, D.A. Specific IgA Enhances the Transcytosis and Excretion of Hepatitis A Virus. Sci Rep. 2016, 6, 21855. [CrossRef]

9. $\quad$ Feng, Z.; Hensley, L.; McKnight, K.L.; Hu, F.; Madden, V.; Ping, L.; Jeong, S.H.; Walker, C.; Lanford, R.E.; Lemon, S.M. A pathogenic picornavirus acquires an envelope by hijacking cellular membranes. Nature 2013, 496, 367-371. [CrossRef]

10. Wang, X.; Ren, J.; Gao, Q.; Hu, Z.; Sun, Y.; Li, X.; Rowlands, D.J.; Yin, W.; Wang, J.; Stuart, D.I.; et al. Hepatitis A virus and the origins of picornaviruses. Nature 2015, 517, 85-88. [CrossRef]

11. Hirai-Yuki, A.; Hensley, L.; Whitmire, J.K.; Lemon, S.M. Biliary Secretion of Quasi-Enveloped Human Hepatitis A Virus. mBio 2016, 7, e01998-16. [CrossRef]

12. Locarnini, S.A.; Coulepis, A.G.; Kaldor, J.; Gust, I.D. Coproantibodies in hepatitis A: Detection by enzyme-linked immunosorbent assay and immune electron microscopy. J. Clin. Microbiol. 1980, 11, 710-716. [CrossRef]

13. Blank, C.A.; Anderson, D.A.; Beard, M.; Lemon, S.M. Infection of polarized cultures of human intestinal epithelial cells with hepatitis A virus: Vectorial release of progeny virions through apical cellular membranes. J. Virol. 2000, 74, 6476-6484. [CrossRef] 
14. Dotzauer, A.; Brenner, M.; Gebhardt, U.; Vallbracht, A. IgA-coated particles of Hepatitis A virus are translocalized antivectorially from the apical to the basolateral site of polarized epithelial cells via the polymeric immunoglobulin receptor. J. Gen. Virol. 2005, 86 Pt 10, 2747-2751. [CrossRef] [PubMed]

15. Dotzauer, A.; Heitmann, A.; Laue, T.; Kraemer, L.; Schwabe, K.; Paulmann, D.; Flehmig, B.; Vallbracht, A. The role of immunoglobulin A in prolonged and relapsing hepatitis A virus infections. J. Gen. Virol. 2012, 93 Pt 4, 754-760. [CrossRef] [PubMed]

16. Tjon, G.M.; Coutinho, R.A.; van den Hoek, A.; Esman, S.; Wijkmans, C.J.; Hoebe, C.J.; Wolters, B.; Swaan, C.; Geskus, R.B.; Dukers, N.; et al. High and persistent excretion of hepatitis A virus in immunocompetent patients. J. Med. Virol. 2006, 78, 1398-1405. [CrossRef] [PubMed]

17. Yotsuyanagi, H.; Koike, K.; Yasuda, K.; Moriya, K.; Shintani, Y.; Fujie, H.; Kurokawa, K.; Iino, S. Prolonged fecal excretion of hepatitis A virus in adult patients with hepatitis A as determined by polymerase chain reaction. Hepatology 1996, $24,10-13$. [CrossRef]

18. Costa-Mattioli, M.; Allavena, C.; Poirier, A.S.; Billaudel, S.; Raffi, F.; Ferre, V. Prolonged hepatitis A infection in an HIV-1 seropositive patient. J. Med. Virol. 2002, 68, 7-11. [CrossRef]

19. Shalimar. Gut microbiome and liver diseases. J. Clin. Exp. Hepatol. 2014, 4, 267-268. [CrossRef]

20. Ishizaka, A.; Koga, M.; Mizutani, T.; Parbie, P.K.; Prawisuda, D.; Yusa, N.; Sedohara, A.; Kikuchi, T.; Ikeuchi, K.; Adachi, E.; et al. Unique Gut Microbiome in HIV Patients on Antiretroviral Therapy (ART) Suggests Association with Chronic Inflammation. Microbiol. Spectr. 2021, 9, e0070821. [CrossRef]

21. Vujkovic-Cvijin, I.; Sortino, O.; Verheij, E.; Sklar, J.; Wit, F.W.; Kootstra, N.A.; Sellers, B.; Brenchley, J.M.; Ananworanich, J.; Loeff, M.S.V.; et al. HIV-associated gut dysbiosis is independent of sexual practice and correlates with noncommunicable diseases. Nat. Commun. 2020, 11, 2448. [CrossRef] [PubMed]

22. Parbie, P.K.; Mizutani, T.; Ishizaka, A.; Kawana-Tachikawa, A.; Runtuwene, L.R.; Seki, S.; Abana, C.Z.; Kushitor, D.; Bonney, E.Y.; Ofori, S.B.; et al. Dysbiotic Fecal Microbiome in HIV-1 Infected Individuals in Ghana. Front. Cell. Infect. Microbiol. 2021, 11, 646467. [CrossRef] [PubMed]

23. Pinto-Cardoso, S.; Klatt, N.R.; Reyes-Teran, G. Impact of antiretroviral drugs on the microbiome: Unknown answers to important questions. Curr. Opin. HIV AIDS 2018, 13, 53-60. [CrossRef] [PubMed]

24. Armstrong, A.J.S.; Shaffer, M.; Nusbacher, N.M.; Griesmer, C.; Fiorillo, S.; Schneider, J.M.; Preston Neff, C.; Li, S.X.; Fontenot, A.P.; Campbell, T.; et al. An exploration of Prevotella-rich microbiomes in HIV and men who have sex with men. Microbiome 2018, 6, 198. [CrossRef]

25. Noguera-Julian, M.; Rocafort, M.; Guillen, Y.; Rivera, J.; Casadella, M.; Nowak, P.; Hildebrand, F.; Zeller, G.; Parera, M.; Bellido, R.; et al. Gut Microbiota Linked to Sexual Preference and HIV Infection. Ebiomedicine 2016, 5, 135-146. [CrossRef]

26. Bolyen, E.; Rideout, J.R.; Dillon, M.R.; Bokulich, N.A.; Abnet, C.C.; Al-Ghalith, G.A.; Alexander, H.; Alm, E.J.; Arumugam, M.; Asnicar, F.; et al. Reproducible, interactive, scalable and extensible microbiome data science using QIIME 2. Nat. Biotechnol. 2019, 37, 852-857. [CrossRef]

27. Callahan, B.J.; McMurdie, P.J.; Rosen, M.J.; Han, A.W.; Johnson, A.J.; Holmes, S.P. DADA2: High-resolution sample inference from Illumina amplicon data. Nat. Methods 2016, 13, 581-583. [CrossRef]

28. Quast, C.; Pruesse, E.; Yilmaz, P.; Gerken, J.; Schweer, T.; Yarza, P.; Peplies, J.; Glockner, F.O. The SILVA ribosomal RNA gene database project: Improved data processing and web-based tools. Nucleic Acids Res. 2013, 41, D590-D596. [CrossRef]

29. Ishizaka, A.; Sato, H.; Nakamura, H.; Koga, M.; Kikuchi, T.; Hosoya, N.; Koibuchi, T.; Nomoto, A.; Kawana-Tachikawa, A.; Mizutani, T. Short Intracellular HIV-1 Transcripts as Biomarkers of Residual Immune Activation in Patients on Antiretroviral Therapy. J. Virol. 2016, 90, 5665-5676. [CrossRef]

30. Chalin, A.; Lefevre, B.; Devisme, C.; Pronier, C.; Carriere, V.; Thibault, V.; Amiot, L.; Samson, M. Serum CXCL10, CXCL11, CXCL12, and CXCL14 chemokine patterns in patients with acute liver injury. Cytokine 2018, 111, 500-504. [CrossRef]

31. Wasmuth, H.E.; Lammert, F.; Zaldivar, M.M.; Weiskirchen, R.; Hellerbrand, C.; Scholten, D.; Berres, M.L.; Zimmermann, H.; Streetz, K.L.; Tacke, F.; et al. Antifibrotic effects of CXCL9 and its receptor CXCR3 in livers of mice and humans. Gastroenterology 2009, 137, 309-319.e3. [CrossRef] [PubMed]

32. Zhang, X.; Shen, J.; Man, K.; Chu, E.S.; Yau, T.O.; Sung, J.C.; Go, M.Y.; Deng, J.; Lu, L.; Wong, V.W.; et al. CXCL10 plays a key role as an inflammatory mediator and a non-invasive biomarker of non-alcoholic steatohepatitis. J. Hepatol. 2014, 61, 1365-1375. [CrossRef] [PubMed]

33. Chalin, A.; Lefevre, B.; Devisme, C.; Barget, N.; Amiot, L.; Samson, M. Circulating levels of CXCL11 and CXCL12 are biomarkers of cirrhosis in patients with chronic hepatitis C infection. Cytokine 2019, 117, 72-78. [CrossRef] [PubMed]

34. Flier, J.; Boorsma, D.M.; Bruynzeel, D.P.; Van Beek, P.J.; Stoof, T.J.; Scheper, R.J.; Willemze, R.; Tensen, C.P. The CXCR3 activating chemokines IP-10, Mig, and IP-9 are expressed in allergic but not in irritant patch test reactions. J. Investig. Dermatol. 1999, 113, 574-578. [CrossRef]

35. Geissmann, F.; Cameron, T.O.; Sidobre, S.; Manlongat, N.; Kronenberg, M.; Briskin, M.J.; Dustin, M.L.; Littman, D.R. Intravascular immune surveillance by CXCR6+ NKT cells patrolling liver sinusoids. PLoS Biol. 2005, 3, e113. [CrossRef]

36. Olson, T.S.; Ley, K. Chemokines and chemokine receptors in leukocyte trafficking. Am. J. Physiol. Regul. Integr. Comp. Physiol. 2002, 283, R7-R28. [CrossRef] 
37. Ida, S.; Tachikawa, N.; Nakajima, A.; Daikoku, M.; Yano, M.; Kikuchi, Y.; Yasuoka, A.; Kimura, S.; Oka, S. Influence of human immunodeficiency virus type 1 infection on acute hepatitis A virus infection. Clin. Infect. Dis. 2002, 34, 379-385. [CrossRef]

38. Zhou, Y.; Callendret, B.; Xu, D.; Brasky, K.M.; Feng, Z.; Hensley, L.L.; Guedj, J.; Perelson, A.S.; Lemon, S.M.; Lanford, R.E.; et al. Dominance of the CD4(+) T helper cell response during acute resolving hepatitis A virus infection. J. Exp. Med. 2012, 209, 1481-1492. [CrossRef]

39. Fenwick, C.; Joo, V.; Jacquier, P.; Noto, A.; Banga, R.; Perreau, M.; Pantaleo, G. T-cell exhaustion in HIV infection. Immunol. Rev. 2019, 292, 149-163. [CrossRef]

40. Vallbracht, A.; Maier, K.; Stierhof, Y.D.; Wiedmann, K.H.; Flehmig, B.; Fleischer, B. Liver-derived cytotoxic T cells in hepatitis A virus infection. J. Infect. Dis. 1989, 160, 209-217. [CrossRef]

41. Walker, C.M.; Feng, Z.; Lemon, S.M. Reassessing immune control of hepatitis A virus. Curr. Opin. Virol. 2015, 11, 7-13. [CrossRef] [PubMed]

42. Fensterl, V.; Grotheer, D.; Berk, I.; Schlemminger, S.; Vallbracht, A.; Dotzauer, A. Hepatitis A virus suppresses RIG-I-mediated IRF-3 activation to block induction of beta interferon. J. Virol. 2005, 79, 10968-10977. [CrossRef] [PubMed]

43. Qu, L.; Feng, Z.; Yamane, D.; Liang, Y.; Lanford, R.E.; Li, K.; Lemon, S.M. Disruption of TLR3 signaling due to cleavage of TRIF by the hepatitis A virus protease-polymerase processing intermediate, 3CD. PLoS Pathog. 2011, 7, e1002169. [CrossRef]

44. Yang, Y.; Liang, Y.; Qu, L.; Chen, Z.; Yi, M.; Li, K.; Lemon, S.M. Disruption of innate immunity due to mitochondrial targeting of a picornaviral protease precursor. Proc. Natl. Acad. Sci. USA 2007, 104, 7253-7258. [CrossRef] [PubMed]

45. Wang, D.; Fang, L.; Wei, D.; Zhang, H.; Luo, R.; Chen, H.; Li, K.; Xiao, S. Hepatitis A virus 3C protease cleaves NEMO to impair induction of beta interferon. J. Virol. 2014, 88, 10252-10258. [CrossRef] [PubMed]

46. Lanford, R.E.; Feng, Z.; Chavez, D.; Guerra, B.; Brasky, K.M.; Zhou, Y.; Yamane, D.; Perelson, A.S.; Walker, C.M.; Lemon, S.M. Acute hepatitis A virus infection is associated with a limited type I interferon response and persistence of intrahepatic viral RNA. Proc. Natl. Acad. Sci. USA 2011, 108, 11223-11228. [CrossRef] [PubMed]

47. Lu, H.; Wu, Z.; Xu, W.; Yang, J.; Chen, Y.; Li, L. Intestinal microbiota was assessed in cirrhotic patients with hepatitis B virus infection. Intestinal microbiota of HBV cirrhotic patients. Microb. Ecol. 2011, 61, 693-703. [CrossRef] [PubMed]

48. Xu, M.; Wang, B.; Fu, Y.; Chen, Y.; Yang, F.; Lu, H.; Chen, Y.; Xu, J.; Li, L. Changes of fecal Bifidobacterium species in adult patients with hepatitis B virus-induced chronic liver disease. Microb. Ecol. 2012, 63, 304-313. [CrossRef]

49. Wei, X.; Yan, X.; Zou, D.; Yang, Z.; Wang, X.; Liu, W.; Wang, S.; Li, X.; Han, J.; Huang, L.; et al. Abnormal fecal microbiota community and functions in patients with hepatitis B liver cirrhosis as revealed by a metagenomic approach. BMC Gastroenterol. 2013, 13, 175. [CrossRef]

50. Aly, A.M.; Adel, A.; El-Gendy, A.O.; Essam, T.M.; Aziz, R.K. Gut microbiome alterations in patients with stage 4 hepatitis C. Gut Pathog. 2016, 8, 42. [CrossRef]

51. Ilhan, Z.E.; Marcus, A.K.; Kang, D.W.; Rittmann, B.E.; Krajmalnik-Brown, R. pH-Mediated Microbial and Metabolic Interactions in Fecal Enrichment Cultures. mSphere 2017, 2, e00047-17. [CrossRef] [PubMed]

52. Duncan, S.H.; Louis, P.; Thomson, J.M.; Flint, H.J. The role of $\mathrm{pH}$ in determining the species composition of the human colonic microbiota. Environ. Microbiol. 2009, 11, 2112-2122. [CrossRef] [PubMed]

53. Kakiyama, G.; Pandak, W.M.; Gillevet, P.M.; Hylemon, P.B.; Heuman, D.M.; Daita, K.; Takei, H.; Muto, A.; Nittono, H.; Ridlon, J.M.; et al. Modulation of the fecal bile acid profile by gut microbiota in cirrhosis. J. Hepatol. 2013, 58, 949-955. [CrossRef]

54. Li, M.; Liu, S.; Wang, M.; Hu, H.; Yin, J.; Liu, C.; Huang, Y. Gut Microbiota Dysbiosis Associated with Bile Acid Metabolism in Neonatal Cholestasis Disease. Sci. Rep. 2020, 10, 7686. [CrossRef] [PubMed]

55. Pinto-Cardoso, S.; Lozupone, C.; Briceno, O.; Alva-Hernandez, S.; Tellez, N.; Adriana, A.; Murakami-Ogasawara, A.; Reyes-Teran, G. Fecal Bacterial Communities in treated HIV infected individuals on two antiretroviral regimens. Sci. Rep. 2017, 7, 43741. [CrossRef] 